\title{
Advanced Manufacturing and Machining Processes
}

\author{
Alborz Shokrani ${ }^{1, *}$ and Dirk Biermann ${ }^{2}$ (D) \\ 1 Department of Mechanical Engineering, University of Bath, Bath BA2 7AY, UK \\ 2 Institute of Machining Technology, TU Dortmund University, 44227 Dortmund, Germany; \\ dirk.biermann@tu-dortmund.de \\ * Correspondence: a.shokrani@bath.ac.uk; Tel.: +44-1225-38-6588
}

Received: 21 October 2020; Accepted: 26 October 2020; Published: 27 October 2020

Manufacturing is one of the major sections of the economy along with services, construction and agriculture. Metal cutting and machining are probably the most used manufacturing processes for making precision engineering parts. Even components manufactured by near net-shaped processes, such as forging and additive manufacturing, require a degree of finish machining in order to achieve the desired geometrical accuracy and surface integrity to fulfil the functional requirements for certain applications. Therefore, machining is widely used for producing parts in aerospace, automotive, space, satellite, medical, electronics and consumer product industries.

The demand for high performance products has resulted in an increased use of advanced material and alloys which can withstand severe mechanical and thermal loads sometimes in harsh environments. These properties often result in difficulties in manufacturing leading to high costs and low productivity. On the other hand, the need for more sustainable yet high quality manufacturing has driven industries and scientists to pursue innovative solutions to reduce the impacts of manufacturing on the environment through enhancing the processes, increasing tool life, reducing resource consumption and improving part quality.

This Special Issue entitled "Advanced Manufacturing and Machining Processes" is dedicated to recent novel technological enhancements in manufacturing and machining processes. Overall, 12 papers are published in this Special Issue ranging from the use of artificial neural networks for predicting and modelling machining behaviour to new tool geometries and cooling lubrication systems, as well as sustainability assessment of machining processes. This Special Issue covers new advancements in the turning, milling, drilling and grinding of different materials.

Heinzel et al. [1] proposed a new method using Barkhausen noise for assessing thermally induced damage to parts following the Malken analytical method for thermally induced surface and subsurface changes in the grinding of steel components. Mirifar et al. [2] developed a new artificial neural network for predicting surface roughness and cutting forces in grinding. They used conventional cutting parameters as well as acoustic emissions from the machine in order to train the network.

Platt et al. [3] developed a setup for thermally assisted micromilling in which the workpiece is heated conductively to various temperatures for machining hardened steel components. This has resulted in thermal softening of the material, leading to enhanced machinability through reduced tool wear and burr formation. Adeniji et al. [4] proposed a model to investigate the impact of size effect on surface roughness and burr formation in machining polycarbonate thermoplastic polymer as a widely recyclable material. Brown and Schoop [5] developed an experimentally validated geometric model for predicting surface roughness based on feed rate, tool geometry, machine tool error and material characteristics in finish turning operations. Denkena et al. [6] proposed a long short term memory (LSTM) neural network to reconstruct cutting forces based on the drive signals of a five-axis milling centre. This would ultimately allow for monitoring cutting forces during machining without the need for a dynamometer force measurement platform. 
Baumann et al. [7] proposed a novel method for preventing regenerative excitement of the machining system in order to minimise vibrations during milling operations by introducing asymmetries in the cutting tool. Wang et al. [8] proposed a method for dynamic error compensation in robotic milling and drilling using laser interferometry. The proposed method significantly improved the position accuracy for robotic machining.

Lakner and Hardt [9] developed a new experimental setup to simulate machining conditions for measuring friction in material cutting. The proposed setup allows for the direct comparison of different lubrication methods in machining. De Bartolomeis and Shokrani [10] realised a new lubrication method based on electrohydrodynamic atomisation for high speed machining of Ti6Al4V titanium alloy which significantly enhances tool life.

Demarbaix et al. [11] investigated the machinability of yttrium oxide tetragonal zirconia polycrystal ceramic material in green state by varying cutting speed and binder percentage. Bhat et al. [12] presented a new algorithm for assessing the sustainability of machining processes which was validated using a cryogenic machining case study.

The outcome of this Special Issue indicates that the new material developments with enhanced properties, requirements for high precision and high-quality products, and the demand for sustainability and low manufacturing costs are driving innovations in manufacturing and machining processes.

We would like to take this opportunity to thank the authors who contributed to the success of this Special Issue as well as the reviewers whose contribution was vital for ensuring the high quality of the papers. We would also like to thank the JMMP Editor in Chief as well as the JMMP staff for giving us this opportunity and for their patience and support throughout the process.

Funding: This research received no external funding.

Conflicts of Interest: The authors declare no conflict of interest.

\section{References}

1. Heinzel, J.; Sackmann, D.; Karpuschewski, B. Micromagnetic Analysis of Thermally Induced Influences on Surface Integrity Using the Burning Limit Approach. J. Manuf. Mater. Process. 2019, 3, 93. [CrossRef]

2. Mirifar, S.; Kadivar, M.; Azarhoushang, B. First Steps through Intelligent Grinding Using Machine Learning via Integrated Acoustic Emission Sensors. J. Manuf. Mater. Process. 2020, 4, 35. [CrossRef]

3. Platt, T.; Meijer, A.; Biermann, D. Conduction-Based Thermally Assisted Micromilling Process for Cutting Difficult-to-Machine Materials. J. Manuf. Mater. Process. 2020, 4, 34. [CrossRef]

4. Adeniji, D.; Schoop, J.; Gunawardena, S.; Hanson, C.; Jahan, M. Characterization and Modeling of Surface Roughness and Burr Formation in Slot Milling of Polycarbonate. J. Manuf. Mater. Process. 2020, 4, 59. [CrossRef]

5. Brown, I.; Schoop, J. An Iterative Size Effect Model of Surface Generation in Finish Machining. J. Manuf. Mater. Process. 2020, 4, 63. [CrossRef]

6. Denkena, B.; Bergmann, B.; Stoppel, D. Reconstruction of Process Forces in a Five-Axis Milling Center with a LSTM Neural Network in Comparison to a Model-Based Approach. J. Manuf. Mater. Process. 2020, 4, 62. [CrossRef]

7. Baumann, J.; Wirtz, A.; Siebrecht, T.; Biermann, D. Disturbance of the Regenerative Effect by Use of Milling Tools Modified with Asymmetric Dynamic Properties. J. Manuf. Mater. Process. 2020, 4, 67. [CrossRef]

8. Wang, Z.; Zhang, R.; Keogh, P. Real-Time Laser Tracker Compensation of Robotic Drilling and Machining. J. Manuf. Mater. Process. 2020, 4, 79. [CrossRef]

9. Lakner, T.; Hardt, M. A Novel Experimental Test Bench to Investigate the Effects of Cutting Fluids on the Frictional Conditions in Metal Cutting. J. Manuf. Mater. Process. 2020, 4, 45. [CrossRef]

10. De Bartolomeis, A.; Shokrani, A. Electrohydrodynamic Atomization for Minimum Quantity Lubrication (EHDA-MQL) in End Milling Ti6Al4V Titanium Alloy. J. Manuf. Mater. Process. 2020, 4, 70. [CrossRef] 
11. Demarbaix, A.; Ducobu, F.; Preux, N.; Petit, F.; Rivière-Lorphèvre, E. Green Ceramic Machining: Influence of the Cutting Speed and the Binder Percentage on the Y-TZP Behavior. J. Manuf. Mater. Process. 2020, 4, 50. [CrossRef]

12. Bhat, P.; Agrawal, C.; Khanna, N. Development of a Sustainability Assessment Algorithm and Its Validation Using Case Studies on Cryogenic Machining. J. Manuf. Mater. Process. 2020, 4, 42. [CrossRef]

Publisher's Note: MDPI stays neutral with regard to jurisdictional claims in published maps and institutional affiliations.

(C) 2020 by the authors. Licensee MDPI, Basel, Switzerland. This article is an open access article distributed under the terms and conditions of the Creative Commons Attribution (CC BY) license (http://creativecommons.org/licenses/by/4.0/). 